\title{
STEM \& Health: Stressors on the Circulatory System
}

\section{Catherine Stanley $^{1}$, Rebecca M. Krall ${ }^{2}$, Kim Zeidler-Watters ${ }^{3}$, Diane Johnson ${ }^{4}$, Rachel R. Blackwell ${ }^{5}$, and Robin L. Cooper ${ }^{1}$}

${ }^{1}$ University of Kentucky, Department of Biology, 675 Rose St, Lexington KY 40506-0225 USA

${ }^{2}$ University of Kentucky, Department of STEM Education, 105 Taylor Education Bldg, 597 S Upper St, Lexington, KY 40406-0001 USA

${ }^{3}$ Eastern Kentucky University, 202 Perkins Building, 521 Lancaster Ave, Richmond KY 40475 USA ${ }^{4}$ Morehead State University, MSU Teach, 102 Lloyd Cassity Bldg, 121 E. Second St, Morehead KY 40351 USA

${ }^{5}$ Morehead State University, Craft Academy for Excellence in Science and Mathematics, 102 Lloyd Cassity Bldg, 121 E. Second St, Morehead KY 40351 USA

(cest242@g.uky.edu; rebecca.krall@uky.edu; kim.zeidler@eke.edu; jdian72@gmail.com; RLCO0P1@uky.edu)

The goal of this problem-based module is to explore the effects of health-related issues (e.g., obesity, arteriosclerosis) on pressures in the circulatory system. Modeling and engineering design are key practices comprising the Next Generation Science Standards, making these modules timely and well-suited for life science classrooms at the introductory college level. These STEM modules bridge standard-based biology, physics, and health concepts in an integrative approach to learn fluid dynamics and physiology in authentic situations. Physiological issues represented include: (1) plaque formation and effect on flow, (2) elastic recoil and arteriosclerosis, (3) effects of blood viscosity on flow, and (4) differential blood pressure related to resistance. Exercises guide learners in assembling and using human circulatory system models to explore principles of pressures as they related to tubing, flow, and resistance. Findings from the investigations are used to construct diagnoses and recommended treatments for patients in realistic scenarios with a secondary emphasis on a healthy lifestyle.

Keywords: problem-based learning, cardiovascular module, physics, health, physiology

Link to Original Poster File: https://doi.org/10.37590/able.v41.poster82

\section{Introduction}

Practical scenarios can provide authentic contexts for unraveling and making sense of complex systems while providing motivation and purpose for learning (Sadler, 2009). Such practices also can help students develop and apply scientific practices (Coll et al., 2005). Using models to explore and construct scientific explanations also promotes metacognitive thinking, communication skills, and creates opportunities for students to participate in the development of scientific knowledge (Gilbert et al. 2000). The use of physical models with guided inquiry additionally supports the conceptual nature of the topic (Coll et al.
2005; Ucar and Trundle 2011). Further, in defining components of a complex biological problem students and teachers can progress through increasingly complex objectives in a logical, stepwise progression to find possible solutions.

The activities that comprise the module were developed for a summer teacher institute to model innovative transdisciplinary activities integrating science and engineering practices and engineering design.

The module is divided into three activities created around a practical but hypothetical situation addressing critical health issues relating to the cardiovascular system, which are relevant to students and their families 
as well as other stakeholders beyond the classroom. The hypothetical situation presents a 50-year old science teacher planning to join her daughter on a trek along the Continental Divide Trail in the Rocky Mountains. In preparation for her trip, she schedules an appointment with her physician to confirm she is healthy enough for the adventure. The class is tasked with interpreting her test results and exploring specific factors that affect the circulatory system and their patient. They then construct physical models the physician can use to explain the teacher's health problems that make her participation on the hike a dangerous undertaking.

These exercises offer a trans-disciplinary model for problem solving that includes application of mathematics, biology, physics, and engineering concepts. Through hypothesis testing, participants design, build, and use physical models to explore and test fluid dynamics as it relates to circulatory issues presented in the patient's test results. Materials used in the activities are easily accessible from hardware construction stores and general-purpose stores, such as Walmart, Kmart, or the Dollar Store. In addition, four YouTube videos accompany this article to demonstrate possible ways to assemble and use the circulatory models.

Students participate in engineering design as they plan, build, and use physical models to explore the physiological processes presented in the scenarios. The process of model design and redesign promotes scientific conceptual understanding and scientific literacy (Berland and Busch, 2012; Fortus et al. 2004; Grossmanet al. 2012; Minogue and Jones, 2006). Further, they apply their knowledge to explain how the model illustrates the phenomenon (Diaz and Cox, 2013; Lachapelle and Cunningham, 2007; Mehalik et al. 2008; Minogue and Jones, 2006; Silk et al. 2009).

Through support of a guided inquiry approach, students build the physical models in the context of engineering design. This challenges students to explore a natural phenomenon and explain how the model illustrates the scientific concepts and processes observed (Barron et al., 1998; Petrosino, 1998; Windschitl et al. 2008). In the case presented in the cardiovascular system (CVS) module, students research physiological processes presented in the patient's test results and then use this information to build models that can explain the biological processes illustrated therein. These learning experiences foster understanding of biological processesand physics principles and build literacy and investigative research skills through the use of journal articles and other resources that guide the planning and design of the constructed models. Taken together, the module presents rich situated learning experiences (Sadler, 2009) that build students' health advocacy skills as they learn to demonstrate major health issues affecting many older Americans today.

The concepts and activities that follow are aligned with the Next Generation Science Standards (NGSS; Achieve, Inc., 2013) in life science, and address big ideas in life science; physical science; engineering, technology and its applications; and mathematics. More specifically, the secondary performance expectation to plan and conduct investigations to provide evidence that feedback mechanisms maintain homeostasis. The module activities also include performance expectations addressing core ideas in physical science; engineering, technology and its applications; and practices in mathematics. Specifically, the lessons address fluid dynamics as it relates to flow through tubes varying in diameter and with varying levels of fluid viscosity. Refer to Table 1 for a detailed list of science standards.

Table 1. Cardiovascular Module Connections to General Science Standards

Plan and conduct an investigation to provide evidence that feedback mechanisms maintain homeostasis.

Develop and use models to illustrate that energy at the macroscopic scale can be accounted for as a combination of energy associated with the motion of particles (objects) and energy associated with the relative position of particles.

Design and build and refine a device that works within given constraints to convert one form of energy into another form of energy.

Design a solution to a complex real-world problem by breaking it down into smaller, more manageable problems that can be solved through engineering. 


\section{Student Outline}

\section{Objectives}

Students will learn:

- how to create and work with physical models to explore a phenomenon (tubes and pump models).

- the general anatomy of the cardiovascular system, relevant subsystems, and practical health-related terms associated with the cardiovascular system.

- the physics of fluid flow and pulsatile pressures of the heart simulated in the cardiovascular models.

- how the health of a person affects their ability to partake in physical activities.

- that the environment can have an effect of the physiology of a person.

\section{Introduction}

What happens if your circulatory system is not healthy? Would it affect your ability to participate in outdoor activities such as hiking, skiing, or riding a bicycle? Your level of physical fitness could be the one factor that changes your vacation plans from embarking on a week long hiking adventure in the mountains to enjoying the pictures of your friends' hiking adventure. The following scenario introduces you to such a case. Through your study of the cardiovascular system, atherosclerosis, and the danger of occluded blood vessels at high elevations, physician explain the choice Cindy will have to make. First, let's start with the conceptual problem.

\section{Cindy Goes to the Doctor}

Cindy, a 40-year old high school teacher, is planning a summer trip with her teenage daughter trekking along the Continental Divide Trail in Colorado and Wyoming. According to the Trails.com web site (http://www.trails.com/continental-divide-trail.aspx),

The Continental Divide Trail might well be the most extreme of the three major National Scenic Trails. The "CDT" covers the greatest distance at approximately 3,100 miles, reaches an ultimate high point of 14,270 feet at Grays Peak, Colorado, and has a low point of 4,280 feet, less than 2,400 feet below the highest point on the Appalachian Trail."

The trip Cindy and her daughter have planned will be very strenuous as they traverse the high-altitude peaks. Is Cindy healthy enough to safely complete the trip? That is the question her physician must answer.

\section{Cindy's Health History}

For the past few years, Cindy's health has been declining. She was in very good shape in high school as a member of the cross-country track team. However, through college and thereafter, her physical fitness and eating habits began a steep decline. After completing college, she became a high school biology teacher in Lexington, KY (elevation 978 feet) and has not made much time for exercise or eating healthy meals. She enjoys a lunch of diet soda, chips and an occasional candy bar, and low-quality dinners that require little preparation, such as spaghetti from a can or a quick meal from KFC. As a result, she has gained considerable weight since beginning her career in teaching. Although Cindy really wants to go on this trip with her daughter, she wants to make sure she is "healthy enough" to do so. She has scheduled a checkup with her physician before beginning her training for the trip.

\section{Cindy's Physical Check Up}

Upon learning of Cindy's plans to hike the Continental Divide, her physician performed a complete physical. She measured Cindy's weight and blood pressure, checked her pulse, listened to her lungs, tested her reflex reactions, and examined her abdominal region. The physician drew blood and ordered a complete blood work up, including a complete lipid panel to check Cindy's cholesterol and triglycerides. The physician was concerned because Cindy was 5 ' 5 ' and weighed 175 pounds, bordering on obesity levels. She was greatly concerned about Cindy's ability to function normally in the high altitudes of the Continental Divide.

\section{Check Up Results}

The results from the physical were of concern. A comparison of Cindy's blood pressure at her ankle and brachial arteries measured greater than the acceptable and healthy levels of $15 \mathrm{mmHg}$ difference (Ankle-Brachial Index $[\mathrm{ABI}]$ is measured by dividing the higher of the two blood pressure measurements at the arms by the higher of the two measures near the ankle (Bonham, 2012; Hoe et al., 2012; Sarangi et al., 2012; Wound, Ostomy and 
Continence Nurses Society, 2012). Cindy's blood pressure in the right arm is 160/95 and she is considered overweight by $40 \mathrm{lbs}$ for her height and body structure. The physician ordered a Doppler ultrasound and a stress test to assess her circulatory and cardiac function.

Upon her follow-up visit, the physician reported to Cindy the lab and test results along with specific recommendations. Cindy's blood analysis revealed a HDL (high density lipids) of $40 \mathrm{mg} / \mathrm{dL}$ and an LDL (low density lipids) of $165 \mathrm{mg} / \mathrm{dL}$. The total cholesterol is $210 \mathrm{mg} / \mathrm{dL}$. The hemoglobin level is $11 \mathrm{gm} / \mathrm{dL}$ with a hematocrit of $36 \%$. The ABI was 0.80 , which indicated poor blood flow to the ankle or brachial arteries. Doppler ultrasonography revealed poor circulation in Cindy's femoral and carotid arteries. Cindy's right femoral artery was about $50 \%$ occluded and her carotid arteries were both about $25 \%$ occluded due to plaque buildup. The physician suggested a conventional angiography of her circulatory system to examine for severe problem points in her circulatory system, including her coronary arteries because she performed poorly on the treadmill stress test.

The physician advises Cindy that her health is not physically fit for the strenuous hiking trip along the Continental Divide at such an altitude and further notes that training for the hiking trip also could be dangerous in her unhealthy state. The physician recommends medications to start reducing the plaque buildup in her arteries and dietary control of lipid and cholesterol intake. The physician also suggests another test to determine whether Cindy has a nutritional deficiency in iron and $B_{12}$ or an underlying disease that might be responsible for the low hemoglobin and hematocrit values.

\section{Designing a Demonstration Model}

Cindy is in denial about her health status. She explains to the physician that she will just stand and walk around her classroom while teaching and will begin walking each evening. She reasons that if she increases the distance and elevation of the walk she takes each night, she will get back in shape for the hiking trip, which is still a month and a half away. She said she does not think the narrowing of her arteries should have much impact on her workouts because she has not experienced any physical issues up to this point. She does not understand the physician's concern that the blood pressures in her leg and arm are so different. She feels a better diet would be good and plans to start on this diet modification right away. However, she does not see the need to take the drugs the physician called a statin. She informed the physician that it was good to have thin blood with a low hematocrit so the blood will flow better at high altitude. Since she was planning to go stay with her daughter in Denver the week prior to starting the hike, she reasoned that her blood likely would get thicker during her initial time there. She has heard that blood becomes thicker when one stays in the high mountains like those outside Denver.

The physician is very frustrated with Cindy's denial of her health status. When Cindy returns for her followup appointment, the physician is determined to use visual models to demonstrate to Cindy what is happening within her blood vessels; the potential reasons for the underlying disease accounting for the low hemoglobin and hematocrit values; and why hypertension is dangerous for her health. The physician also plans to demonstrate with the models the impact of altering her hematocrit with her present conditions. With the help of the physician's brother, a physics instructor at the local college she recruits a group of college biology and physics students to design models that can be used to demonstrate the issues involved in the problems mentioned: ankle-brachial index, atherosclerosis, and viscosity of flow in constricted tubes. You are part of the college student team.

\section{Lesson 1: Modeling the Plaque Buildup: Resistance to Flow}

The goals of this first lesson are to use physical models to learn how the physics of fluid dynamics explain the issues of atherosclerosis - the narrowing of arteries that occurs through the progression of this condition.

Atherosclerosis, also referred to as hardening of the arteries, is commonly a result of multiple plaques building up along the arterial walls. Plaques build up in the circulatory system from a diet high in fats, such as Cindy's frequent fast food dinners of fried chicken with a side of french fries. The result of this buildup is narrowing of the arteries. When the blood vessel narrows it also creates turbulent blood flow. The swirling motion of the blood can deposit more plaques, increasing the potential for blood clots to form in these regions. There are various stages in the severity of atherosclerosis with the most severe stage resulting in the lining of the blood vessel breaking down and hemorrhaging, releasing blood into the surrounding body tissues.

In this first lesson, it might be good to work in teams of three and four to explore the effects of narrowing the channels on the flow of blood through the "blood vessels". Plastic tubes and colored water can be used to simulate the blood vessels and blood flow, respectively, and varying sizes of binder clips and "glue plaque" can be used to simulate occlusions in the vessels. In addition, it would be helpful to read about the mechanics of blood flow through the circulatory system and the health risks from hypertension in order to build your knowledge (Wang et al., 2006).

There are several ways to create plaque buildup in the model. A realistic approach is making a glue plaque as it is easily observed when mixing colored fingernail polish in a clear epoxy mix. The epoxy can be applied to the 
inside lining of a clear plastic tube. The tube is filled with water and a coupling is used to make the tube connected for water flow. Fine sand or black pepper can be added to the water to make the turbulence of the water flow over the plaque more visible. These tiny pieces represent plaques and other small particles found in blood flow. Small pebbles or large grains of sand also can be placed in the water to illustrate how particles such as fatty plaques in the blood can be caught on the edges of the glue plaque, simulating the formation of blood clots.

The following YouTube link presents the steps in construction and demonstration of the turbulent flow and clots: http://youtu.be/KHxOwnh4YVo

\section{Lesson 2: Ankle-brachial Index}

The second lesson focuses on the ankle-brachial index (ABI), which is a non-invasive procedure to screen for peripheral arterial disease of large vessels. This can be associated with diabetes and lower extremity arterial disease (American Diabetes Association, 2003; WOCN Clinical Practice Wound Subcommittee, 2012). The procedure is performed by comparing systolic blood pressures in the ankle to the higher of the brachial systolic blood pressures of the upper arm. Thus, if a blockage is present in a large blood vessel in the leg, the systolic blood pressure past the block will be lower than before it. The ankle is the lowest place in the leg to readily obtain a blood pressure with a blood pressure cuff. The systolic pressure will then be higher in the brachial (upper arm) compared to the ankle, so the ratio (ankle/brachial) will be lower than in a person without any blockage in the large vessels in the leg.

To design a model to represent ankle-brachial differences, two tubes that branch off from a primary line of the tube circulatory system model can be used to obtain visual measures in the height of fluid or gauges can be used to directly measure pressures quantitatively. Clamps can be placed at various locations along branching tubes to observe the effect constrictions might have along the blood vessel. Conversely, using clamps of varying strength can demonstrate the constricting effect when plaque forms along a blood vessel in comparison to an occlusion formed when plaque eventually blocks the vessel.

A YouTube link presents the steps in construction and demonstration of the pressure differences in two regions of a simulated cardiovascular system:

$$
\text { https://www.youtube.com/watch?v=XVr-MT3k0mw\&feature=youtu.be }
$$

\section{Lesson 3: Atherosclerosis Loss of Elastic Recoil - Windkessel Effect}

The atherosclerosis (hardening of the arteries) will not only result in restriction of flow in the arteries but will also reduce the elasticity of the vessels. Of particular concern is the loss of elasticity in the aorta since it dampens the large systolic pressure wave by extending and maintaining diastolic pressure with its recoil. This is referred to as the Windkessel effect (Wang et al., 2005). With the loss of elasticity one can imagine the effect as a pulse wave of water enters a narrowed steel pipe. The pressure will first be high at the peak of the wave and then drop quickly as the pulse wave passes. However, if the pulse wave enters a rubber tube, which can expand and recoil, the peak pressure will be dampened by the elastic extension and the recoil will help to maintain the pressure wave after the peak has passed. In the human model the systolic and diastolic pressures will have a greater difference in values in someone with atherosclerosis of the aorta as compared to a healthy circulatory system $(120 / 60)$.

The Windkessel effect is easily modeled with a pump bottle, a tube, and a balloon. To demonstrate the steel pipe analogy described above, the pump bottle is attached directly to the tube. As the pump bottle is squeezed, the peak wave is apparent as pressure exerted from the pump forces water through the tube. However, soon thereafter the pressure drops, and the water movement greatly slows. Adding a small balloon between the pump and the tube illustrates the effect when the vessel can expand with the passing of the peak pressure wave and then recoil, creating pressure within the vessel even after the pressure wave have passed. A peripheral branch of the tube after the connector can be used as a means to measure the pressure wave. Some downstream resistance can be applied to represent afterload the pump has to work against.

A YouTube link presents the steps in construction and demonstration of the Windkessel effect in relation to systolic and diastolic blood pressure: http://youtu.be/UJt3-IGnhVU

\section{Discussion}

To summarize the learning from the four lessons, develop a recommendation for Cindy. Do you recommend that she accompany her daughter on the hiking trip? Consider Cindy's medical record in your response. Provide a comparison between the values a healthy person would be expected to have and relate them to Cindy's reported values. In addition, accurately use key medical and physiological terms (e.g., atherosclerosis, hematocrit, Windkessel effect, ankle-brachial index) introduced in the exercises in the explanations. Describe how the models demonstrate specific health conditions that Cindy's test results reveal and use them to illustrate how her conditions could affect her health if she attempted the hiking adventure. 
Working in groups, prepare a short, informal presentation to illustrate how the model demonstrates the effects of atherosclerosis on the cardiovascular system. Peer review between groups may be helpful to modify and improve models and explanations. Follow up discussions also may be helpful to improve the models or question the accuracy of the simulation.

\section{Cited References}

American Diabetes Association 2003. Peripheral arterial disease in people with diabetes. Diabetes Care 26:3333-3341. doi: 10.2337/diacare.26.12.3333 PMID:14633825

Bonham P. 2012. WOC consult: misconceptions about the ankle brachial index. Journal of Wound, Ostomy Continence Nursing 39:1-2.

Coll RK, France B, Taylor I. 2005. The role of models/and analogies in science education: Implications from the research. International Journal of Science Education 27(2):183-198.

Cooper RL, Zeidler K, Johnson D, Wilson J. 2017. The healthy flea market. Connected science learning. National Science Teachers Association (NSTA). Online January 16, 2017. Available at: http://csl.nsta.org/2017/01/thehealthy-flea-market/

Gilbert JK, Boulter CJ, Elmer R. 2000. Positioning models in science education and in design and technology education. In JK Gilbert and CJ Boulter (Eds.), Developing models in science education. Dordrecht, The Netherlands: Kluwer.

Hoe J, Koh WP, Jin A, Sum CF, Lim SC, Tavintharan S. 2012. Predictors of decrease in ankle-brachial index among patients with diabetes mellitus. Diabetic Medicine 29(9):e304-7. doi: 10.1111/j.1464-5491.2012.03705.x. PMID: 22587456

Sarangi S1, Srikant B, Rao DV, Joshi L, Usha G. 2012. Correlation between peripheral arterial disease and coronary artery disease using ankle brachial index-a study in Indian population. Indian Heart Journal 64(1):2-6. doi:10.1016/S0019-4832(12)60002-9.

Wang JJ, Flewitt JA, Shrive NG, Parker KH, Tyberg JV. 2006. Systemic venous circulation. Waves propagating on a windkessel: relation of arterial and venous windkessels to systemic vascular resistance American journal of physiology. Heart and circulatory physiology. 290:H154-H162. doi:10.1152/ajpheart.00494.2005

West JB. 2004. The physiologic basis of high-altitude diseases. Ann Intern Med. 141:789-800

Whayne TF Jr. 2014. Cardiovascular medicine at high altitude. Angiology 2014 65(6):459-72. doi: $10.1177 / 0003319713497086$.

Wound, Ostomy and Continence Nurses Society 2012. Ankle brachial index quick reference guide for clinicians. Journal of Wound, Ostomy Continence Nursing 39(2S): S21-S29.

WOCN Clinical Practice Wound Subcommittee 2012. Journal of Wound, Ostomy \& Continence Nursing: 39(2S): S21S29. doi: 10.1097/WON.0b013e3182478dde 


\section{Materials}

The following materials are needed to perform these activities:

\section{Circular Hose Experiments}

- $2 \times 45$ inches of tubing (total 90 inches) with $1 / 2$ inch outer diameter (OD) and $3 / 8$ inch inner diameter (ID); Excelthane Polyurethane Tubing, Part \# 54501 US Plastics

- 2 couplings for $3 / 8$ inch hose - we used 1/2 to 3/8 inch Poly-E Reducer Connector (Part \# 062019 US Plastics)

- Pebbles

- Super Glue ${ }^{\circledR}$ to glue mass for simulated atherosclerosis

- Water

- Black Pepper (spice) for seeing the water flow and turbulence of flow

\section{Differential Flow Model}

- 2 × 60 inches of tubing \& 1 × 12 inches of tubing (total 132 inches) with $3 / 16$ inch OD $\times 1 / 8$ inch ID $x$ 1/32 inch wall width (WW), Excelthane Polyurethane Tubing, Part \# 54501 US Plastics Corp)

- $2 \times 25$ inches, $1 \times 60$ inches of tubing (total 110 inches); 1/4 inch OD x 3/16 inch ID x 1/32 inch WW, Excelthane Polyurethane Tubing, Part \# 54504 US Plastics

- 2 T-couplings for 3/16 OD hose (They work when forced; Part \# 064345 US Plastics)

- $\quad$ One 3-way stopcock to fit hose (1/8 inch ID); (Sigma-Aldrich part S7521 - 10 per pack, stopcock 3-way Luer lock)

- 50 or $60 \mathrm{ml}$ syringe (Sigma-Aldrich, Part \# Z683698, 30 per pack; or US Plastics, $60 \mathrm{cc} / \mathrm{ml}$ Dispensing Syringe, 3/16 inch ID x 6 1/2 inch length (Part 66384, Manufacturer: Plas-Pak, Manufacturer Part \# 60B12/C12B)

- $\quad$ Red food coloring

- Water

- Plastic shoe box or dish basin to catch excess water

- Twist ties

- A wire frame to hold the model (Walmart: Whitmor Black Wire Storage Cubes, set of 4; need $1 / 2$ of the kit for each group project)

\section{Vertical Flow}

- 2 plastic funnels, wide neck $(9 \mathrm{~mm} \times 43 \mathrm{~mm}$ stem, 50 mm top; Sigma-Aldrich part Z637548, 24 per pack)
- Various size tubing that slip into each other with about 5 inches each, beginning with 11/16 inch OD then getting smaller to $3 / 16$ inch OD

- A wire frame to hold each group model (Walmart: Whitmor Black Wire Storage Cubes, set of 4 , need $1 / 2$ of kit for projects)

- Water

- Plastic shoe box to catch excess water

- 2 beakers or cups

- Food coloring

- Pinch clamp or a clothes pin

- Pancake syrup

- Stopwatch or timer on smart phone

- Twist ties

\section{Windkessel Effect Pressure}

- 8 feet of $3 / 8$ inch ID hose/tubing

- One T connector (to fit a 3/8 inch ID hose/tube) (Home Depot: Watts brand Polyurethane Tubing, Part \# A-291)

- Yard stick

- Plastic shoe box or dish basin to collect waste water

- Pinch clamp or clothes pins

- $\quad$ Pump Gallon bottle with pump (Part \# 66078 US Plastics; Gallon Translucent Bottle and Pump 38mm Cap)

- Water

- Party balloons (long thin ones) to fit the tubing

- A wire frame to hold the model (Walmart: Whitmor Black Wire Storage Cubes, set of 4; need $1 / 2$ of kit for each group project)

- Twist ties

\section{Notes for the Instructor}

\section{Preparing Students for Interpreting Cindy's Health Status}

The integrative nature of the exercise is in researching how high altitude may alter the viscosity of the blood and how the viscosity of the blood is an issue with atherosclerosis increasing the risk of blood clotting. Physical model building can illustrate various aspects, but a higher level of integration is being able to draw relationships, such as the relationship between the increased risk of blood clots at high altitudes and the medical conditions presented for Cindy. The students will need to research key medical and physiological terms (i.e., atherosclerosis, hematocrit, Windkessel effect, ankle-brachial-index etc.) introduced in Cindy's story. Through their building and manipulating models, they also will need to research key physiological processes and other terms presented to make reasonable connections between 
their findings and Cindy's health issues. Ultimately, the goal of the proceeding exercises is for students to translate new biological and physics knowledge and scientific and engineering practices in the context of health issues Cindy and likely someone in their families might currently be experiencing. Thus, it creates real-world context for their learning. Materials and tutorial videos are provided to support planning and building models. The videos are posted on YouTube for easy access to illustrate how to assemble the models for each of the proceeding exercises.

\section{Assessment}

An assessment check is needed to measure student learning during and after model construction and use. An evaluation should address the level of scientific understanding and the ability of the designed models to accurately simulate results of occluded blood vessels. In the teacher institute, each small group made short, informal presentations to the entire group to illustrate their model and explain the ways in which it demonstrated the effects of atherosclerosis. Follow up discussions gave the audience opportunities to make suggestions on ways to improve the models or question the accuracy of the simulation. This was quite informative for redesigning the physical model.

Other assessment options for the students could include lesson checks and written summaries. The instructor might informally meet with each group to discuss the working models and how they simulate turbulent flow and the potential for blood clot formation. Written summaries also can be used to assess student understanding. However, in either case, time should be allotted for student groups to receive critique from other groups and exchange ideas for improving their models, and time to make improvements. This is an essential component of engineering design and testing of models, critiquing their usefulness and feasibility, and making updates to improve the model.

In addition, assessment of the learning could include a team project designed to be presented at an educational heath fair. Public presentation of the findings from a classroom investigative activity that is based on a practical situation can be informative for the student researchers as well as the public. Further, it can promote better health for the students and the public. This was attempted in 2017 after working with a high school class in rural Kentucky. At a public event, students were able to present hearts and tissue from cadavers, with permission from the University of Kentucky, and under supervision of a designated faculty member. In addition, students presented finding from their research on the related topics covered in this exercise (Cooper et al., 2017).

\section{Crossing Disciplines}

There are other uses for these flow dynamic models. The basic concepts of fluid dynamics are illustrated with these models such as resistance and flow in the narrow tubes. The pressure differential before and after resistance can be a building block for addressing Bernoulli's principles. There is a parallel to fluid flow in a city water drainage system and pressures which can blow a manhole cover off the street when flow is restricted or the fluid dynamics behind water drainage from rain gutters. Another abstract of a correlation can be made to the flow of electricity as well with flow and resistance. Thus, the models could be shared among biology and physics classrooms within a school for illustrating the basic principles and how they relate to different situations.

The viscosity module with the pancake syrup is a little messy so make sure to use some protective rag or plastic floor covering when conducting this module. This was really the only module which required substantial clean up. The use of plastic tubes and easily assembled bookshelf racks allows for easy storage in bins for following classes.

\section{Cited References}

American Diabetes Association 2003. Peripheral arterial disease in people with diabetes. Diabetes Care 26:3333-3341.

doi: 10.2337/diacare.26.12.3333 PMID:14633825

Bonham P. 2012. WOC consult: misconceptions about the ankle brachial index. Journal of Wound, Ostomy Continence Nursing 39:1-2.

Coll RK, France B, Taylor I. 2005. The role of models/and analogies in science education: Implications from the research. International Journal of Science Education 27(2):183-198.

Cooper RL, Zeidler K, Johnson D, Wilson J. 2017. The healthy flea market. Connected science learning. National Science Teachers Association (NSTA). Online January 16, 2017. Available at: http://csl.nsta.org/2017/01/the-healthy-flea-market/

Gilbert JK, Boulter CJ, Elmer R. 2000. Positioning models in science education and in design and technology education. In JK Gilbert and CJ Boulter (Eds.), Developing models in science education. Dordrecht, The Netherlands: Kluwer.

Hoe J, Koh WP, Jin A, Sum CF, Lim SC, Tavintharan S. 2012. Predictors of decrease in ankle-brachial index among patients with diabetes mellitus. Diabetic 
Medicine 29(9): e304-7. doi: 10.1111/j.14645491.2012.03705.x. PMID: 22587456

Wang JJ, Flewitt JA, Shrive NG, Parker KH, Tyberg JV. 2006. Systemic venous circulation. Waves propagating on a indkessel: relation of arterial and venous windkessels to systemic vascular resistance American journal of physiology. Heart and circulatory physiology. 290:H154-H162, doi:10.1152/ajpheart.00494.2005

NGSS Lead States. 2013. Next Generation Science Standards: For States, By States. Washington, DC: The National Academies Press.

Sadler TD. 2009. Situated learning in science education: socio-scientific issues as contexts for practice. Studies in Science Education 45(1):1-42.

Sarangi S1, Srikant B, Rao DV, Joshi L, Usha G. 2012. Correlation between peripheral arterial disease and coronary artery disease using ankle brachial index-a study in Indian population. Indian Heart Journal 64(1):2-6. doi:10.1016/S0019-4832(12)60002-9.

Whayne TF Jr. 2014. Cardiovascular medicine at high altitude. Angiology 2014 65(6):459-72.

doi: $10.1177 / 0003319713497086$.

Wound, Ostomy and Continence Nurses Society 2012. Ankle brachial index quick reference guide for clinicians. Journal of Wound, Ostomy Continence Nursing 39(2S):S21-S29.

WOCN Clinical Practice Wound Subcommittee 2012. Journal of Wound, Ostomy \& Continence Nursing: 39(2S):S21-S29.

doi: 10.1097/WON.0b013e3182478dde

\section{Acknowledgments}

Funded by Kentucky Department of Education Science Leadership Support Network to PIMSER and personal funds (RLC). We thank Dr. Christine Schnittka for the suggestion to make the modules small enough and easy to assemble and store in classrooms.

\section{About the Authors}

Catherine Stanley is a graduate student pursuing a master's degree in Biology at the University of Kentucky. She received her BS in both Biology and Neuroscience from the University of Kentucky. Her current research focus involves the effects of $\mathrm{pH}$ on synaptic transmission.

Rebecca Krall earned an undergraduate degree in elementary education from Virginia Tech in 1988, K-8 certification in science and literacy. After teaching science in grades six through eight, she earned a masters and doctorate in science education from the University of Virginia. She currently teaches science methods and effective uses of technology at the University of Kentucky. Her current research interests include developing K-8 teachers' scientific knowledge and pedagogy for creating authentic science experiences for students, and teachers' awareness of student thinking in PIMSER

Kim Zeidler-Watters is the Director of

Diane Johnson serves as a Master Teacher with MSUTeach at Morehead State University in Morehead, Kentucky. Diane is a Regional Teacher Partner with PIMSER at Eastern Kentucky University, a member of the Professional Learning Cadre with NSTA, and on the Peer Review Panel for Achieve.

Rachel Rogers Blackwell is a doctoral candidate pursuing a $\mathrm{PhD}$ in STEM Education at the University of Kentucky. She received a Bachelor of Science in Biology, Bachelor of Art in Speech Communication, Master of Arts in Teaching, and an Instructional Specialist degree from Morehead State University. Rachel holds a National Board Teaching Certificate in Biological Science. She is the Research Project Manager for the Craft Academy for Excellence in Science and Mathematics at Morehead State University.

Robin Cooper is an instructor of animal physiology and neurophysiology at the University of Kentucky. He received a double major with a BS from Texas Tech in 1983 and a PhD in Physiology from Texas Tech Medical School in 1989. He has been at the University of Kentucky since 1996. 


\section{Mission, Review Process \& Disclaimer}

The Association for Biology Laboratory Education (ABLE) was founded in 1979 to promote information exchange among university and college educators actively concerned with teaching biology in a laboratory setting. The focus of ABLE is to improve the undergraduate biology laboratory experience by promoting the development and dissemination of interesting, innovative, and reliable laboratory exercises. For more information about ABLE, please visit http://www.ableweb.org/.

Advances in Biology Laboratory Education is the peer-reviewed publication of the conference of the Association for Biology Laboratory Education. Published articles and extended abstracts are evaluated and selected by a committee prior to presentation at the conference, peer-reviewed by participants at the conference, and edited by members of the ABLE Editorial Board. Published abstracts are evaluated and selected by a committee prior to presentation at the conference.

\section{Citing This Article}

Stanley C, Krall RM, Zeidler-Watters K, Johnson D, Blackwell RR, Cooper RL. 2020. STEM \& health: stressors on the circulatory system. Article 82 In: McMahon K, editor. Advances in biology laboratory education. Volume 41. Publication of the 41st Conference of the Association for Biology Laboratory Education (ABLE). https://doi.org/10.37590/able.v41.art82

Compilation (C) 2020 by the Association for Biology Laboratory Education, ISBN 1-890444-17-0. All rights reserved. No part of this publication may be reproduced, stored in a retrieval system, or transmitted, in any form or by any means, electronic, mechanical, photocopying, recording, or otherwise, without the prior written permission of the copyright owner.

ABLE strongly encourages individuals to use the exercises in this volume in their teaching program. If this exercise is used solely at one's own institution with no intent for profit, it is excluded from the preceding copyright restriction, unless otherwise noted on the copyright notice of the individual chapter in this volume. Proper credit to this publication must be included in your laboratory outline for each use; a sample citation is given above. 